\title{
Walter Benjamin, uma biografia: De uma vida tornada obra
}

\section{Luciana Araujo Marques}

Universidade Estadual de Campinas (UNICAMP), Campinas, São Paulo / Brasil araujo.lu@gmail.com

Publicado em 1985, na Alemanha, Walter Benjamin, de Bernd Witte, foi lançado apenas em 2017 no Brasil e com o subtítulo uma biografia. Se na opção alemã o nome do filósofo como título poderia sugerir uma não diferenciação entre o que se conta de sua vida e de sua obra, a prescindir de complemento, na brasileira, com tradução de Romero Freitas para a editora Autêntica, a escolha parece chamar a atenção para o fato de o livro preencher uma lacuna em nossas prateleiras. Afinal, apesar das muitas publicações sobre Benjamin no país, nenhuma delas dava conta de sua trajetória biográfica especificamente. Já a edição em língua inglesa, de 1997, opta por adjetivar a natureza da empreitada de Witte. Lêse na capa: Walter Benjamin: An Intellectual Biography. O acréscimo de "intelectual" remonta ao sentido contido naquela interpretação possível do título original, em que vida e obra não se dissociam, o que diz também de uma advertência honesta com relação ao conteúdo que o leitor encontrará em suas páginas, uma vez que a publicação não é o resultado do trabalho de um biógrafo preocupado em esmiuçar a vida de um personagem, mas de um professor e pesquisador que busca na trajetória do filósofo alemão as circunstâncias que deram corpo à sua obra, ainda que tantas vezes um corpo fragmentado e de caráter multifacetado.

Walter Benjamin: uma biografia tem quase 160 páginas, seiscentas menos que, por exemplo, Walter Benjamin: A critical life (2014), de Howard Eiland e Michael W. Jennings, de modo que a concisão da primeira quando comparada à segunda não está ligada à brevidade da vida de seu protagonista, mas justamente ao recorte dado por Bernd Witte, ex-professor de Teoria Literária na Universidade Heine, em Dürsseldorf (Alemanha) e presidente da Sociedade Internacional Walter Benjamin 
(IWBG). Enquanto Eiland e Jennings parecem ressaltar o entroncamento entre a biografia de Benjamin e a história da Europa, Witte se detém em tudo aquilo que possa dar pistas de como se desenvolveu seu trabalho intelectual, tendo os escritos de Benjamin como pontos de partida e chegada. Não à toa, ao tratar da infância do filósofo, Witte recorre às memórias escritas em breves textos pelo próprio em Infância berlinense: 1900, ainda que nelas reconheça muito mais um aspecto profético em retrospectiva do que uma ordem documental histórica.

Desse "mosaico", em que consta um autorretrato fotográfico, o biógrafo depreende o "método do antirromance de formação materialista" benjaminiano, pois Benjamin não trata de si mesmo e aproxima-se de Franz Kafka (aproximação que pode ser feita ao longo de toda a biografia, aliás), uma vez que para ambos a escrita serviu de evasão do meio original. Evasão paradoxal, é verdade, já que os escritos resultam sempre em decantação do vivido, do pensamento colado à matéria que é a experiência.

Essa opção que tem os textos de Benjamin como epicentro, lidos a partir do presente de uma pesquisa e sua perspectiva, pouco opta pela narrativa de "como alguém se tornou o que é", para usar a expressão nietzcheana, porque reforça muito mais que este alguém, que hoje conhecemos depois de tantas leituras e releituras, foi sempre o mesmo, da meninice de alguém nascido em 1892 até seu suicídio em 1940. "Diversamente de outros literatos que apenas após um longo prolongado início encontraram o seu tom próprio, Walter Benjamin é desde o começo ele mesmo em seus escritos" (WITTE, 2017, p. 21), é a afirmação que abre o capítulo que aborda a juventude de Benjamin, por exemplo. Alicerça o período biográfico (mas não apenas ele em sentindo cronológico, como o autor procura ressaltar) um protesto contra a opressão escolar, a casa paterna e a moral burguesa que se estenderá por toda sua vida, ainda que trocados os alvos da crítica.

Essa toada de correspondência entre as diferentes etapas da vida de Benjamin também vale para o tratamento dado à posição metafísica e elitista de Benjamin em relação ao judaísmo, a despeito de sua criação em uma família liberal e não praticante em termos religiosos. Se não há nuvens diante do olhar do jovem quanto à singularidade de seu papel social e de seu condicionamento por ser judeu, tampouco elas enevoariam o ângulo do homem maduro, que também acreditaria na conviç̧ão de que os judeus formariam uma elite entre os seres, pois o judaísmo seria um "nobilíssimo representante e portador do espiritual", segundo suas 
próprias palavras. A respeito dessa afirmação feita em 1912, Witte conclui: "Benjamin manteve essa posição, fundamentalmente, por toda sua vida. Ele ainda a defendeu quando a história real, através da dominação nacional-socialista na Alemanha, transformou em ilusão suas ideias de uma missão europeia do judaísmo" (WITTE, 2017, p. 25), com a ressalva de que não se pode confundir essa posição com a assimilação tradicional da burguesia judaica como prevalência. Tendo em vista que "Benjamin sempre se negou a compreender a própria práxis como puramente social ou política" (WITTE, 2017, p. 26). Eleito presidente da Liga Estudantil Livre de Berlim, Benjamin disse no discurso de abertura do semestre de verão de 1914 que não haveria "ligação interior e originária [...] entre a existência espiritual de um estudante e seu interesse assistencial por filhos de trabalhadores" (BENJAMIN apud WITTE, 2017, p. 27). Fala que foi repetida um mês depois e rechaçada pelos colegas.

Outro dado bastante conhecido da vida de Benjamin, o suicídio de seu amigo, o poeta Fritz Heinle, que tinha a mesma idade dele, junto de Rika Seligson, desesperados por causa da irrupção da Primeira Guerra Mundial, é tratado na biografia como uma "espécie de vivência originária", sempre em relação à sua produção intelectual, com base na interpretação que o próprio Benjamin teria dado ao evento ao escrever sobre Oidiota, de Dostoiévski, em 1917, portanto, um de seus primeiros ensaios. Segundo o filósofo, a grande queixa do escritor russo no livro estaria centrada no fracasso de um movimento da juventude. "Na falta da natureza e da infância, a humanidade só pode ser alcançada em uma autoaniquilação catastrófica" (BENJAMIN apud WITTE, 2017, p. 30). Soma-se à derrocada de um ideal comunitário composto por seres espirituais, então desencarnado na figura do amigo morto, o testemunho melancólico benjaminiano da sobrevivência assinalada como ângulo de seu olhar, tal e qual o dos vencidos da história:

Como sobrevivente, ele dá testemunho da produtividade do poeta e da simultânea aniquilação e consumação do sentido desta através da morte. Ele fez a experiência de que pureza do espírito não se pode encontrar na vida, mas apenas na linguagem poeticamente estruturada, e de que ela não pode se tornar visível e efetiva por meio da práxis social, mas apenas por meio da linguagem da sobriedade, que para ele é falada pela prosa da crítica. (WITTE, 2017, p. 30) 
Assim, a morte, na leitura que Witte faz de Benjamin, é contorno primordial e definitivo da figura do poeta e seu necessário destino trágico, visto que precisa necessariamente perecer, o que equivale até certo ponto à definição que fará mais tarde sobre o drama trágico, "um espetáculo para um público em luto" (BENJAMIN apud WITTE, 2017, p. 64).

"Sobre a linguagem em geral e sobre a linguagem do homem", ensaio escrito por volta de 1916, em que Benjamin diferencia quatro níveis da linguagem (criadora; adâmica; humana contemporânea e a muda das coisas) está no centro de uma autointerpretação que o filósofo trava via cartas com seu amigo Gershom Scholem, atormentado pelas mesmas questões, e que Witte faz questão de sublinhar como exemplo do "quanto a constelação originária do pensamento de Benjamin permaneceu a mesma em meio a todas as transformações" (WITTE, 2017, p. 32). Os esforços por uma comunidade espiritual na juventude como realização judaica de sua parte seriam ainda maiores no que se refere à sua primeira filosofia da linguagem. Desse ensaio como marco biográfico intelectual, sempre carregado pelos afetos do vivido como norte, sobressai um outro tema fundamental na vida/obra de Benjamin: a salvação de experiências não disponíveis ao conhecimento racional. Não à toa Benjamin era um grande leitor de Freud.

Como fechamento do intervalo entre 1912 e 1917, voltamos a ouvir Witte soar a mesma nota. Na articulação dos diferentes projetos desenvolvidos já na juventude (o de uma teoria autônoma como síntese de filosofia da história, crítica literária e teoria da linguagem) o biógrafo localiza "o centro e a origem do pensamento de Benjamin" como "teoria crítica". "A essa teoria ele vincula a expectativa utópica que revela aí a verdade como força imediatamente ativa, transformadora do mundo, messiânica" (WITTE, 2017, p. 34). É curioso nesse sentido, e até certo ponto, sem deixar de considerar todas as especificidades de uma obra ficcional em relação a uma produção ensaística, que Witte chame a atenção para a crítica que o próprio Benjamin faz da biografia de Goethe assinada por Friedrich Gundolf alinhada à teoria literária da época, que concebia a criação poética como reflexo da vida do autor. "Benjamin critica apropriadamente o fato de que Gundolf constrói a vida de Goethe por analogia com uma obra, de modo que por fim a sua vida surge como a sua grande obra, na qual o próprio autor é o herói” (WITTE, 2017, p. 43).

Os dissabores e flutuações da vida financeira de Benjamin, determinante na relação com os pais e suas exigências práticas, o desespero que assolará o burguês na aniquilação de seus privilégios e 
consequente perda de orientação social, assim como a frustração de sua vida amorosa não parecem romper com esse princípio geral de algo que permanece como hipótese biográfica no livro de Witte, uma insistência diante de um personagem complexo e com facetas que variam do que lemos em "Experiência e pobreza" e "O narrador", para ficar nesses casos exemplares, onde parte-se de uma mesma constatação (a perda da experiência) para se chegar a conclusões tão diferentes.

Ainda sobre o escrito de Benjamin sobre As afinidades eletivas, de Goethe, concluído em 1922, registra-se sua dedicatória à escultora Jula Cohn, irmã de um colega de classe. Conheceram-se em 1912 e mais tarde, em 1921, morou com Benjamin e sua esposa, criando impasses para seu casamento, que terminou em divórcio em 1930, novamente por conta da inclinação por Jula. Witte mostra como detalhes que surgem como temática do ensaio em foco teriam sido assunto de conversa com a médica e psicóloga Charlotte Wolff, que conheceu Benjamin em 22. Ela conta que na época discutiram justamente a questão de como grandes obras da literatura se desenvolvem através de problemas pessoais. Evidência, segundo Witte, de que Benjamin identificou no romance semelhanças com sua própria vida amorosa, e mesmo uma indistinção entre os traços de Jula e da literária Otília, dando à sua crítica um "pano de fundo existencial" e à sua não efetividade numa permanência amorosa sólida o acento que será reconhecido como próprio de seu lugar como crítico, ainda que Witte trate logo em seguida de defender essa posição de traços psicológicos restritos ao indivíduo:

Benjamin faz da mulher amada, que é a mais próxima, a mais distante, na medida em que ela a estiliza na figura de Otília; ou seja, faz dela uma amante que se destitui na mais distante distância: a morte. O que o leva a tal distanciamento? Se refletirmos sobre o seu comportamento semelhante em relação a outras mulheres, como Asja Lacis, surge a suposição de que com a defesa contra uma ligação duradoura ele procurava proteger-se, porque ele seria incapaz de suportar a morte do amor no cotidiano. Porém, não se deve falar aqui de fatos psicológicos individuais, mas antes da única forma em que o amor parece ser possível a um grande amante: na renúncia à realização. Benjamin transforma a amada num texto, e o texto na verdadeira amada. Desse objeto amado só é possível aproximar-se através do estudo infinito. (WITTE, 2017, p. 48) 
Algo semelhante se dá no comentário sobre a própria dificuldade para atuar como professor universitário e, de quebra com a Escola de Frankfurt e as circunstâncias que determinavam a forma como liam e renegavam a produção de Benjamin, em atitude "mesquinha", como classifica o biógrafo. Para além do vínculo institucional, o filósofo prezaria mais sua solidão intelectual e sua independência, ainda que isto estivesse lhe custando a própria sanidade mental e financeira. O mesmo pensamento o fazia adiar, por exemplo, sua filiação ao Partido Comunista, o que também não chegou a se efetivar. Benjamin sempre questionava qual seria a viabilidade econômica de uma posição isolada à esquerda, $o$ que resultava em sucessivos recuos em alianças de qualquer tipo, apesar de seus expansivos deslocamentos, como se pode apreender no capítulo "Paris - Berlim - Moscou (1926-1929)", mas não apenas (são inúmeras as viagens do filósofo, tantas que não será possível comentá-las todas nesta resenha, mas sempre relevantes para sua produção). Enquanto a capital francesa foi decisiva para a apreensão da flânerie, a leitura da poesia baudelairiana como exemplo da experiência moderna e a elaboração de suas Passagens - templo secreto das mercadorias, tal síntese e conclusão do ciclo materialista iniciado com Rua de mão única -, a temporada na cidade de Lenin nada tinha que ver com um certo turismo da Revolução, comum entre os intelectuais da época.

Witte lembra que em "O agrupamento político dos escritores da União Soviética", publicado em março de 1927 em O Mundo Literário, Benjamin indica as afinidades políticas como fator de agrupamento de escritores e não mais as estéticas. Não se identificando com os vanguardistas de esquerda, mas com o novo naturalismo russo, ele se posiciona politicamente ao deduzir que "a função da literatura em uma sociedade revolucionária seria a produção da "esfera pública absoluta", a serviço da " "alfabetização' das massas chamadas à sua emancipação política" (WITTE, 2017, p. 80). O papel do escritor nas crises sociais vira mote das resenhas de Benjamin após seu retorno de Moscou, e sua experiência de perda dos privilégios de sua classe de origem já mencionada o opõe à sociedade burguesa: "teve de viver na própria pele a posição mais exposta possível entre a fronda anarquista e a disciplina revolucionária" (BENJAMIN apud WITTE, 2017, p. 82).

Os planos de Benjamin de viver na Palestina, incentivado por seu amigo Scholem, que já havia imigrado em 1923 e se tornado professor na Universidade de Jerusalém, se perdem nesse mesmo cenário de recuos 
e colapsos nervosos, tudo isso somado ao depauperamento, além da já declarada rejeição ao sionismo. Os estudos de hebraico, obrigatórios para que se efetivasse a imigração, eram constantemente adiados e a vida pessoal de Benjamin também não colaborava para seu desenrolar. O longo processo de divórcio de Benjamin e Dora resultou ainda na devolução de um alto dote, para piorar a situação. No mesmo ano do divórcio, sua mãe faleceu, o que desencadeou uma cisão definitiva com a família. Até os 40 anos de idade ele tinha vivido com a mulher e os filhos na villa dos pais, que proporcionaram em grande parte sua vida de viagens constantes. Nesse ponto de sua trajetória, conforme o relato de Witte, sem a ajuda financeira familiar, sem emprego, sem casa ou qualquer outra garantia material, ele encarnava o ideal no qual sempre investiu todas as energias, o do outsider, "vivendo como indivíduo isolado através da escrita e para a escrita” (WITTE, 2017, p. 87).

Em 1920 Benjamin havia concebido a revista Angelus Novus, nome inspirado por uma gravura de Paul Klee, que adquirira em Munique. A publicação não alcançou qualquer êxito, mas a imagem do anjo da história é íntima para os leitores do filósofo, que a relacionam diretamente à sua concepção de história nas Teses, com seu rosto voltado para o passado. O nome da revista foi justificado no final de sua apresentação com a lenda talmúdica dos "Anjos novos", alegoria do método que orientaria os textos, o que gerou uma contradição interna, visto que ela não estaria voltada para leitores humanos, conforme aponta Witte: "Ambos leem nos fragmentos e estilhaços da história mais recente a sua salvação e os levam assim até diante de Deus" (WITTE, 2017, p. 42). Pois em 1939, quando Benjamin se encontrava na França exilado e já sem esperanças de conseguir algum recurso para seguir trabalhando - por conta de uma carta em que Horkeiheimer relatava as dificuldades financeiras do instituto de Nova York -, o Angelus Novus, este símbolo incontornável em sua obra, era o seu último bem (e o mais amado). Tentou, inclusive, vendê-lo para um comprador nos Estados Unidos, para pagar sua passagem à América. Viagem que, como sabemos, nunca ocorreu.

Para Witte, que parece trilhar a hipótese de um princípio de permanência a ser mapeado em diversos pontos da obra benjaminiana entrelaçados sempre aos encontros pessoais ao longo da vida do filósofo, na qual cada afeto experimentado ressoa em suas linhas como sedimentos do vivido, "o despertar do sonho coletivo do século XIX, que Benjamin queria operar em Passagens revela-se [...] como a imagem de desejo de 
um indivíduo que foi deixado sozinho pelo sujeito coletivo da história" (WHITTE, 2017, p. 137). Reflexão com tom de conclusão que vem seguida da menção à fatídica invasão da Polônia pelas tropas de Hitler, em setembro de 1939, quando Benjamim concluía seu ensaio "Sobre alguns motivos na obra de Baudelaire", para logo em seguida ser preso e enviado a um campo, onde permaneceu por três meses até ser solto no final de novembro e poder retornar a Paris, graças à intervenção de amigos influentes na França. Witte encerra esse capítulo com a imagem de um sonho que Benjamin teve no campo, o único relato escrito que fez nesse período: a imagem do corpo de uma mulher muito bonita se fundia em coisa única com a leitura de sinais. "Depois desse sonho eu não pude adormecer de novo, por várias horas. De felicidade." (BENJAMIN apud WITTE, 2017, p. 137).

No capítulo final, "O fim da história (1940)", são tratados os pensamentos que Benjamin dizia ter "resguardado em si por vinte anos, protegendo-os de si mesmo" (BENJAMIN apud WITTE, 2017, p. 140). Tratam-se das Teses sobre o conceito de história que carregam traços de um "testamento intelectual", segundo o biógrafo. Nelas, Benjamin não levaria em conta o momento histórico imediato em que estava imerso, abandonaria o desespero corrente para vislumbrar uma oportunidade de revolução, "sinal de uma paragem messiânica" com redenção plena no Juízo Final, unindo pensamento religioso e político. Esperança que Witte não deixa de associar àquela que Benjamin cita ao comentar o fracasso de Kafka: "Desse modo há, com diz Kafka, esperança infinita, só que não para nós" (BENJAMIN apud WITTE, 2017, p. 142).

Recebido em: 20 de outubro de 2018

Aprovado em: 21 de outubro de 2018 